\title{
SAFEA application design on determining the optimal order quantity of chicken eggs based on fuzzy logic
}

\author{
Sesar Husen Santosa ${ }^{1}$, Agung Prayudha Hidayat ${ }^{2}$, Ridwan Siskandar ${ }^{3}$ \\ ${ }^{1,2}$ Industrial Management Study Program, College of Vocational Studies, IPB University, Bogor, West Java, Indonesia \\ ${ }^{3}$ Computer Engineering Study Program, College of Vocational Studies, IPB University, Bogor, West Java, Indonesia
}

\begin{abstract}
Article Info
Article history:

Received Jan 13, 2021

Revised Sep 2, 2021

Accepted Sep 18, 2021

\section{Keywords:}

Consumer demand

Final stock

Membership function

Optimal order

SAFEA application

ABSTRACT

The availability of stock in the chicken egg supply chain is influenced by the ability of egg Agents to determine the optimal orders to suppliers. The optimal number of orders is very important to manage for the Bogor City Egg Agent Indonesia because the stock capacity reaches 340 crates. The optimal number of orders for eggs at the Egg Agent is influenced by input variables, namely final stock (crate), selling price (crate), and consumer demand (crate) so that the inventory is under control. The three input variables have fuzzy values that must be processed using fuzzy logic to get the optimal number of orders to suppliers so that the egg stock in the warehouse is well maintained. The optimal order model for eggs in the smart application for egg agent (SAFEA) was developed using a fuzzy logic approach with the triangular and trapezoidal membership function. Based on the optimal order model in the SAFEA application, the optimal order to the supplier is $100-104$ crates per day.
\end{abstract}

Selling price
This is an open access article under the $\underline{C C B Y-S A}$ license.

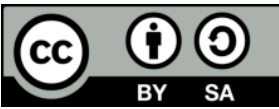

\section{Corresponding Author:}

Sesar Husen Santosa

Industrial Management Study Program

College of Vocational Studies IPB University, Indonesia

IPB Kampus Cilibende J1 Kumbang No 14 Bogor 16151, West Java, Indonesia

Email: sesarhusensantosa@apps.ipb.ac.id

\section{INTRODUCTION}

Smart application for egg agent (SAFEA) is an application that egg agents can use to identify the optimal number of ordered chicken eggs to maintain stock availability, so there is no stock accumulation in the warehouse. The supply chain of chicken eggs has a problem imbalance between supply and demand, which causes the stock of eggs to increase, resulting in the stock of eggs often rotting because not sold. Therefore, we need a decision tool for making the optimal number of egg orders in the form of a smart application to determine the optimal number of orders so that the stock in the warehouse is well maintained. Shou $e t$ al. [1] has suggested the complexity of the product, actor position, and the actor size are influence supply management. The amount of stock and the selling price of chicken eggs are variables that influence optimal consumer purchasing decisions [2]. Supplier management can affect costs, inventory, and product production costs [3].

The optimal number of suppliers is a solution to maintain a balance of supply and demand in supply chain activities. The method used to determine the optimal order is the economic order quantity (EOQ) method. [4], [5] have suggested that the EOQ method is used by considering the conditions of deterministic market demand. The EOQ is used to develop an optimal inventory model to reduce costs and maximize orders [6]. 
The EOQ method can balance supply and demand to maximize the companies procurement function, but the order trend is flat every period [7]. The SAFEA application can determine orders according to fluctuating actual conditions. Godichaud and Amodeo [8] has suggested that the EOQ method can reduce logistics revers based on costs because it can identify the number of requests to maintain inventory. Determining the optimal order in the SAFEA application pays attention to costs and stock conditions, selling prices, and demand so that the amount of stock becomes ideal. Still, in the supply chain activities of chicken eggs, the input variables, namely the final stock (crate), total demand (crate), and selling price (crate), have a crisp value so that it requires a fuzzy logic approach to explain the value.

The current fluctuation in the price of chicken eggs causes egg agents to be unable to determine the optimal number of orders to suppliers to increase ordering costs, and the warehouse accumulates. Selling price and demand can obtain maximum profit, so the company needs to develop a model to identify the maximum profit based on these two variables [9]-[12] have suggested that the fuzzy logic model is a decision making system and optimization model that provides solutions to complexity parameter input. Fuzzy logic models can be used to identify costs incurred for production so that the selling price of the product becomes more optimal so that consumer demand increases [13]. In addition, Fuzzy Logic functions for system tracking accuracy, control, and software security management, and induction machine [14]-[26] have suggested that in addition, it can be helpful to put an object in focus and select and classify an object module. Fuzzy logic can provide recommendations for measurement results that refer to membership and the truth value [27].

Fuzzy logic has been used to determine the ideal conditions for the effectiveness of the production machine so that the production process is well maintained [28]. Fuzzy logic can identify the state of uncertainty in the number of requests so that retailers can produce products that are acceptable to consumers [29]. Optimal order development using fuzzy logic can identify the number of orders according to consumer demand, so egg quality is maintained in the warehouse [30]. has suggested that fuzzy logic can identify each variable's value with a crisp value. Variables that affect the optimal order and have a crisp value are the final stock (crate), total demand (crate), and selling price (crate), so it is necessary to use a fuzzy logic approach to identify the fuzzy value of these variables. Optimal order quantity management can reduce inventory to reduce storage costs, and the product distribution process runs optimally [31]. The designed fuzzy logic can increase the effectiveness of the chicken egg supply chain and reduce costs. Qin et al. [32] has suggested that fuzzy logic can be used in managing supply activities to eliminate waste and can help make decisions regarding the management of raw material supply. The product distribution process can also control the ideal stock condition based on optimal orders. Uncertainty in the number of requests can cause product stock outs in the warehouse, so a fuzzy approach is needed to keep stock conditions stable [33]. Management of big data and information related to supply and demand at retail and manufacture have to manage using technology so that the transaction process that occurs can run quickly and accurately [34]. This optimal order fuzzy model uses supply and demand information but to manage the system upstream.

The optimal ordering model in the SAFEA application can identify data and carry out data processing learning processes based on daily transaction models. This model will continue to study every transaction data that occurs so that the number of orders to suppliers will be optimal. Several recent studies [35]-[37] have suggested that machine learning is needed to get a simple and more accessible method by downloading experiment simulation data packages and creating intelligent decision making [38]-[42] have suggested that machine learning proves the ability of computer algorithms to improve performance over time, handle data more efficiently, select relevant features and power system reliability. Machine learning can improve performance by modeling the transients in the switches, one of which is the agricultural sector [43], [44]. In the future, this machine learning will open up a learning tool industry that promises to solve problems and analyse data than Artificial Intelligence [45]. Based on the balance of supply and demand for chicken eggs, the researcher developed the SAFEA application in which there is a model for determining the optimal number of orders. This application is the first application used by egg agents to identify the optimal number of chicken eggs for suppliers in real time using a fuzzy logic approach. The supply and demand of egg agents are well maintained. Fuzzy logic can identify linguistic variables into variables that have rational numbers for multi-criteria decision making [46]. The optimal number of orders can increase profits to determine product requests to increase profits [47].

\section{RESEARCH METHOD}

The development of the optimal order model in the SAFEA using a fuzzy logic approach. Pourjavad and Shahin [48] has suggested that the development of this fuzzy model uses the Mamdani fuzzy inferences system, where the input will be processed using an inference engine to produce specific results in the defuzzification process of the Crips variable owned. The stages in developing the optimal order fuzzy model in the SAFEA application are:

SAFEA application design on determining the optimal order quantity of chicken... (Sesar Husen Santosa) 


\subsection{Fuzzy membership function}

Fuzzy logic can determine the optimal number of orders based on input and output variables. The input variable is obtained from the actual condition of the egg agent in determining the number of orders which is then developed into a fuzzy system. The inference system used in developing this model is:

- Triangular membership function

Rajesh [49] has suggested that the triangular membership function used when there is one peak value of the degree of freedom of the parameter, namely 1 , in the input and output variables. The parameter values of each variable in this membership set will be adjusted to the condition of the egg agent in managing the transaction process every day. Based on the graph of the membership set above, it can be determined the value of the membership set value $\mu \mathrm{F}(\mathrm{a}, \mathrm{b}, \mathrm{c}): \mathrm{R} \rightarrow[0,1]$.

- $\quad$ Trapezoidal membership function

Rezaei and Ortt [50] has suggested that the trapezoidal membership function used when there is more than one maximum value of degrees of freedom, namely 1 . This membership set is used because there are variables that affect the optimal order having several parameters with a maximum value of membership degree. Based on this membership set graph, the membership set value $\mu \mathrm{F}(\mathrm{a}, \mathrm{b} 1, \mathrm{~b} 2, \mathrm{c})$ : $\mathrm{R} \rightarrow[0,1]$.

\subsection{Fuzzy rule base}

Fuzzy rule base in managing fuzzy Input variables using the "IF THAN ELSE" principle to determine the value of the selected fuzzy operator. The selected fuzzy rules base will be used to calculate the optimal order value during the defuzzification process. The Fuzzy rule base is Ri: If X1 is A1i and X2 is A2i, an Xm is Ami Then Y is $\mathrm{Bi} ; \mathrm{i}=1 ; 2 ; \ldots \mathrm{n}$ with the operator used is "and" so that the selected operator value is the minimum value [51], [52].

\subsection{Defuzzification}

The defuzzification process uses the center of area (COA) method. This method uses the moment value and the width area in the output variable based on the selected fuzzy operator. The formulation of the COA method is:

$$
X \operatorname{coa}=\frac{\int_{x=0}^{n} \mu A(x) x d x}{\int_{x=0}^{n} \mu A(x) d x}
$$

\subsection{Waterfall SDLC method}

The software process model represents the software process from a particular perspective and partial system information that more flexible [53]. The process of making this software is known as the system development life cycle (SDLC) with the creation four phases of a structured software product [54]. SDLC organization refers to secure a software [55]. The waterfall model used for controlling and protecting a sequential development model applied to government projects, small businesses, to thousands of large companies such as medical sector [56], [57]. The work on this model is divided into 6 phases, namely sensing, signal processing, feature extraction, pattern processing, situation assesment, decision making [58] as well as the addition, namely without planned iteration to keep development cost, duration, and resulting product quality [59] adding more approach to develope a software [60].

\section{RESULTS AND DISCUSSION}

Development of SAFEA uses a fuzzy logic approach to determine optimal orders to suppliers. This optimal order model was developed based on the variables that affect the supply and demand of egg agents. The stages of determining the optimal order in the SAFEA application can be seen in the following Figure 1. Variables that influence the development of this model are the final stock of eggs, egg demand, and the selling price of the crate. These three variables will be developed in the form of a membership set based on the actual condition of the egg agent transaction. The development of fuzzy logic on the optimal ordering menu for eggs to suppliers has several stages and uses the Matlab application to create a fuzzy set model. The stages of model simulation and the results of the optimal order defuzzification in the SAFEA application are: 


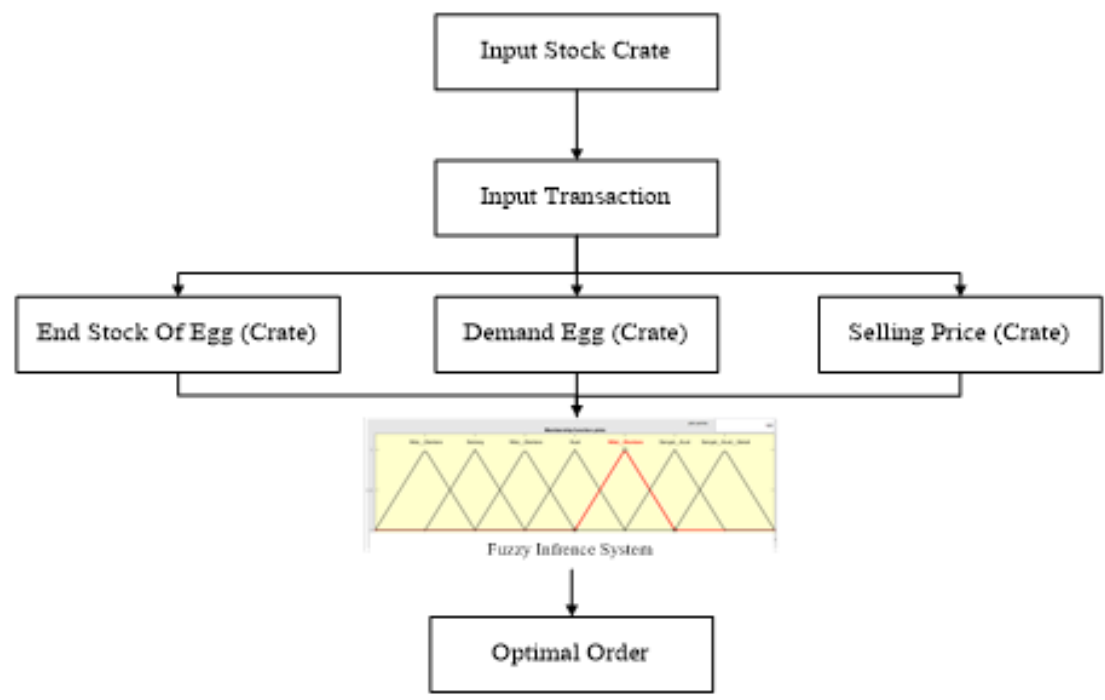

Figure 1. Flow chart for determining optimal order in the SAFEA application

\subsection{Optimal order membership function}

The membership set is built based on actual conditions in the field. The input variables used in the SAFEA application are the selling price, consumer demand, and stock availability at the egg agent. The membership function graph used can be seen in the following Figure 2. The output membership set of this fuzzy model is the optimal number of orders from the egg agent to the supplier based on the condition of the amount of stock, the selling price of eggs, and the demand for eggs.

The graph of the set of variable memberships that affect the optimal number of orders can be seen in Figure 2. Figure 2(a) show the graph of final egg stock membership set uses a combination of triangular and trapezoidal membership functions with the highest parameter value limit is 300 crates. The graph of the egg demand membership set uses 4 parameters. Figure 2(b) show combination of triangular and trapezoidal membership functions with a maximum demand value of 200 crates. Figure 2(c) show the graph of the membership set selling price is determined based on the transaction activities of the egg agent where there are 3 parameters used with the lowest selling price being Rp. 300.000 and the highest selling price being Rp. 380.000 .

The value of the degree of membership that occurs in the three variables that affect the optimal order will then be processed through a defuzzification optimal order. The defuzzification process will be carried out on the optimal order membership set to get the optimal egg order fuzzy value. The optimal order number membership set uses 4 parameters: low, medium, high, and very high. The optimal order fuzzy membership set can be seen in the following Figure 3. The model verification process is carried out by entering the final stock value of 90 crates, and then the end stock membership degree value is $\mu$ end_Stock $(a, b, c)=0,33$. These results show that the final stock condition is in the medium parameter, namely 90 crates, so the degree of membership used to determine the fuzzy operator is 0.33 . The Membership Function for the end stock is as:

$$
\text { Fx (end Stock) }\left\{\begin{array}{cl}
0 & x \leq 0 \\
1 & 0 \leq x \leq 30 \\
\frac{x-40}{15} & 40 \leq x \leq 55 \\
\frac{80-x}{25} & 55 \leq x \leq 80 \\
\frac{x-70}{60} & 70 \leq x \leq 130 \\
\frac{200-x}{70} & 130 \leq x \leq 200 \\
\frac{x-180}{70} & 180 \leq x \leq 250 \\
1 & 250 \leq x \leq 300
\end{array}\right.
$$




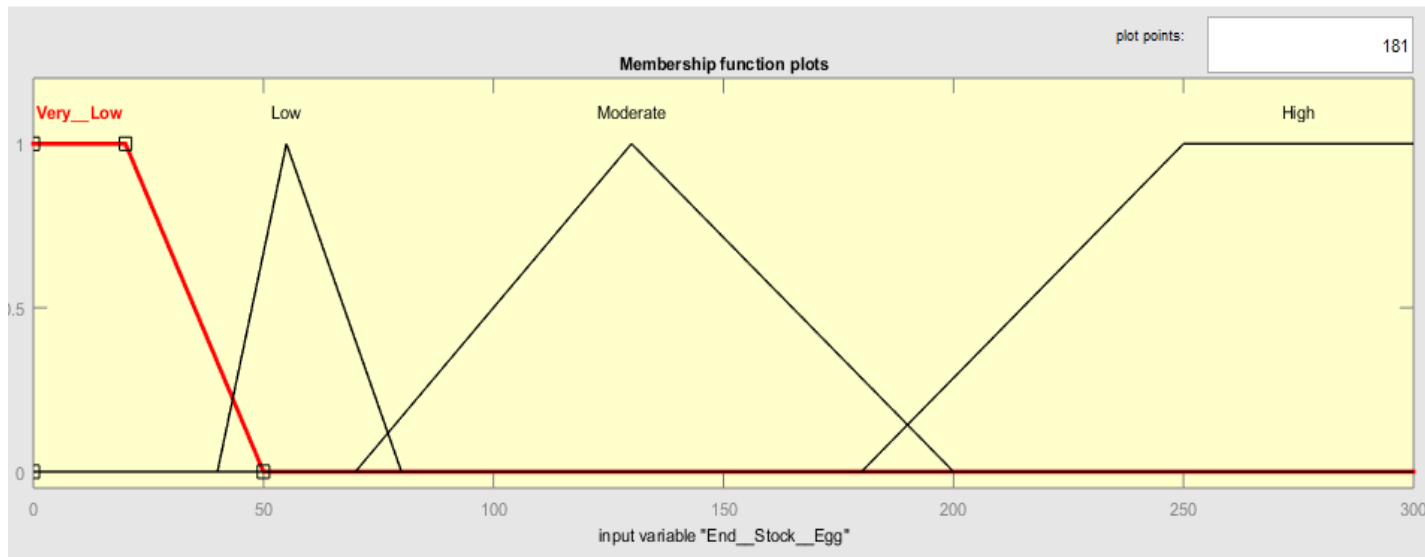

(a)

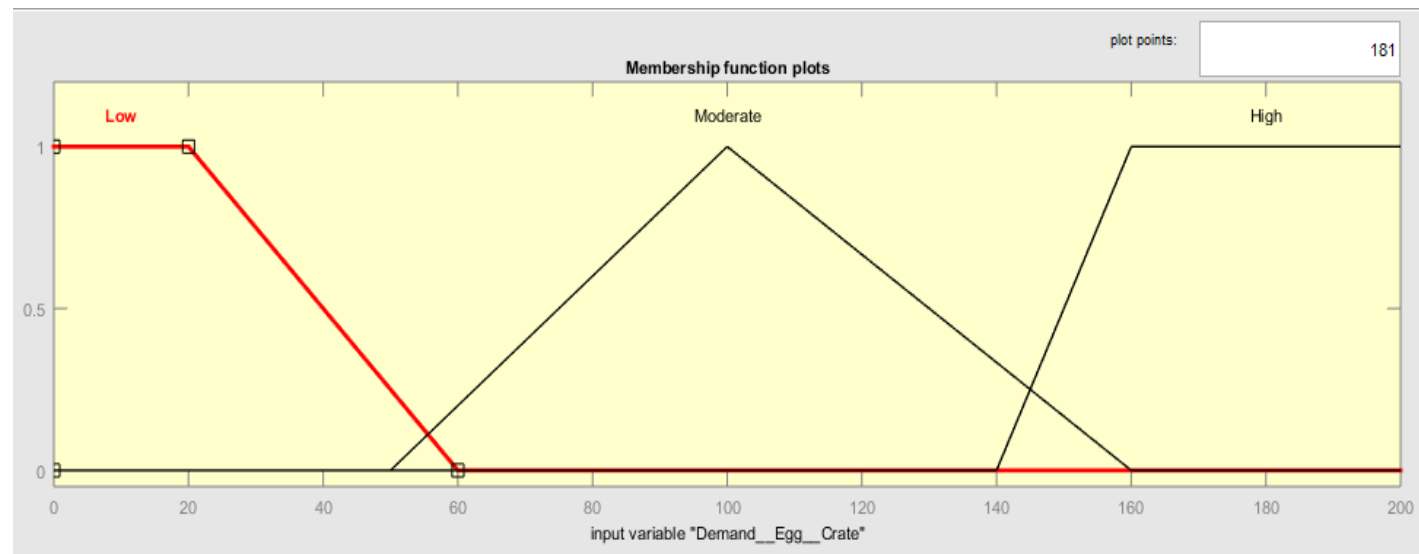

(b)

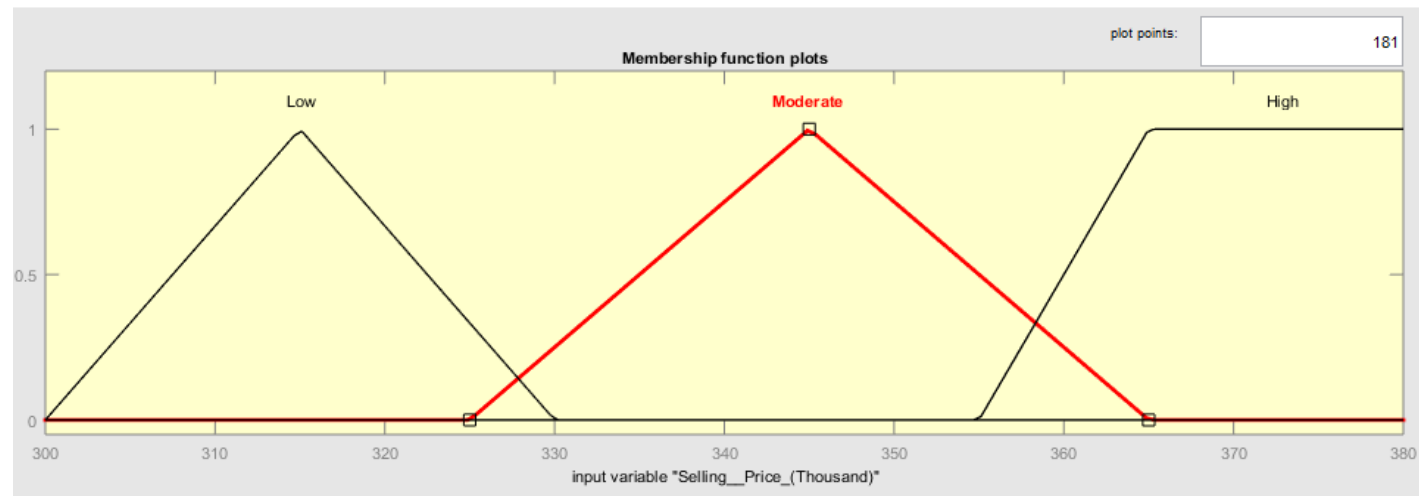

(c)

Figure 2. The graph of the set of variable memberships function that affect the optimal number of orders (a) Stock membership function (crate), (b) demand membership function (crate), (c) selling price membership function (x1000)

Based on the number of requests for 150 crates, the value of the request membership degree is $\mu$ demand $(\mathrm{a}, \mathrm{b}, \mathrm{c})=0,5$. These results show that the demand egg condition is in the medium parameter, namely 150 crates, so the degree of membership used to determine the fuzzy operator is 0,5 . The set of membership requests is: 


$$
\text { Fx (Demand) }\left\{\begin{array}{cl}
0 & x \leq 0 \\
1 & 0 \leq x \leq 20 \\
\frac{60-x}{40} & 20 \leq x \leq 60 \\
\frac{x-50}{50} & 50 \leq x \leq 100 \\
\frac{160-x}{60} & 100 \leq x \leq 160 \\
\frac{x-140}{20} & 140 \leq x \leq 160 \\
1 & 160 \leq x \leq 200
\end{array}\right.
$$

Based on the selling price of Rp. 340,000, the value of the demand membership degree is $\mu$ Selling_Price $(\mathrm{a}, \mathrm{b}, \mathrm{c})=0,75$. These results show that the selling price condition is in the medium parameter, namely $\mathrm{Rp} 340.000$, so the degree of membership used to determine the fuzzy operator is 0,75 . The selling price membership set is:

$$
\text { Fx (Selling Price) }\left\{\begin{array}{cc}
0 & x \leq 300.000 \\
\frac{x-300.000}{15.000} & 300.000 \leq x \leq 315.000 \\
\frac{330.000-x}{15.000} & 315.000 \leq x \leq 330.000 \\
\frac{x-325.000}{20.000} & 330.000 \leq x \leq 345.000 \\
\frac{365.000-x}{20.000} & 345.000 \leq x \leq 365.000 \\
\frac{x-355.000}{10.000} & 355.000 \leq x \leq 365.000 \\
1 & 365.000 \leq x \leq 380.000
\end{array}\right.
$$

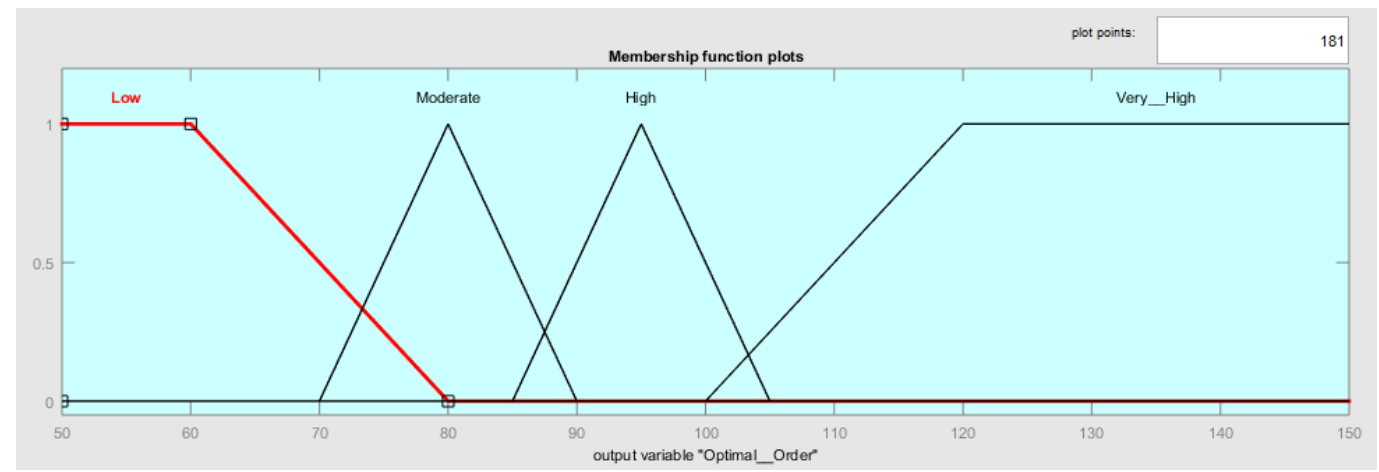

Figure 3. Optimal order membership function

\subsection{Fuzzy rule base}

The next step is to determine the possible fuzzy rule base based on the membership set of input variables and output variables. The rule is based on the "and" operator, and the operator's value is "minimum", then there are 144 possibilities that occur. The simulation of the fuzzy rule base using the rule editor in the Matlab application can be seen in the following Figure 4.

Based on the fuzzy rule base results, it can be determined the value of the operator used in the degree of membership of the optimal order fuzzy. The operator values obtained are:

$$
\alpha=\operatorname{Min}\left(\mu_{\text {Tinggi [1] }} \cap \mu_{\text {Rendah }[0,536]} \cap \mu_{\text {Tinggi [1] }}\right)=\operatorname{Min}(0,33 ; 0,5 ; 0,7)=\alpha=0,33
$$






Figure 4. Fuzzy rule base for optima order in matlab application

\subsection{Optimal order defuzzyfication}

Defuzzification of the optimal ordering of chicken eggs using the COA method by comparing the resulting moment with the area of the optimal ordering output variable. The total moment obtained in the optimal order simulation is 3525.37. Moment based on the results of the optimal order fuzzy membership set is:

$$
\begin{array}{ll}
\int_{50}^{73,4} 0,33 x d x & \int_{85}^{90} 0,1 x 2-8,5 x \\
\int_{70}^{73,3} 0,1 x 2-7 x & \int_{90}^{101,7} 0,33 x d x \\
\int_{73,4}^{80} 4 x-0,05 x 2 & \int_{101,7}^{105} 10,5 x-0,1 x d x \\
\int_{73,4}^{86,7} 0,33 x d x & \int_{100}^{106,6} 0,05 x 2-5 x d x \\
\int_{86,7}^{90} 9 x-0,1 x 2 & \int_{105}^{150} 0,33 x d x
\end{array}
$$

Determining the total width area (WA) in the fuzzy membership set of optimal order is 35.21 . Verification of the area generated by the optimal order membership set is:

$$
\begin{array}{ll}
\text { WA 1 } & =\frac{(73,3-50) \times 0,33}{(73,3-70) \times 0,33} \\
\text { WA 2 } & =\frac{7,689}{2}=0,5445 \\
\text { WA 3 } & =\frac{(80-73,4) \times 0,33}{2}=1,089 \\
\text { WA 4 } & =4,422
\end{array}
$$




WA 5 $=\frac{(90-86,7) \times 0,33}{2}=0,544$
WA 6 $=\frac{(88,3-85) \times 0,33}{2}=0,544$
WA 7 $=4,422$
WA $8=\frac{(105-101,7) \times 0,33}{2}=1,089$
WA 9 $=\frac{(106,6-100) \times 0,33}{2}=14,322$
WA 10 $=\frac{(150-106,6) \times 0,33}{}=1,34 \times 0,33$

Based on the COA method, the optimal order value is 100 Crate by comparing the moment and the area. The verification of optimal order defuzzification using Matlab software showed the same results, namely 100 crates. Optimal order defuzzification of eggs using matlab software can be seen in the following Figure 5.

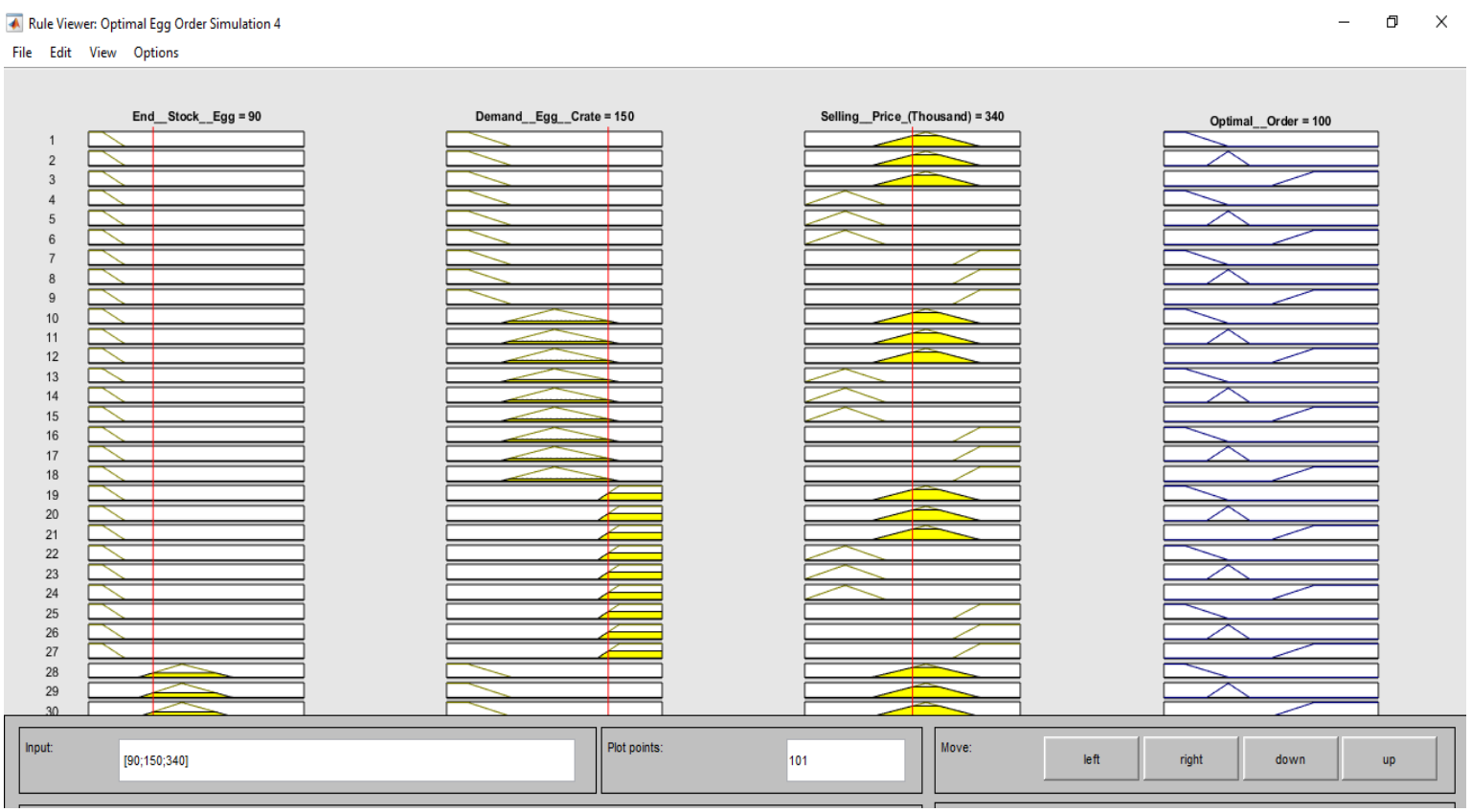

Figure 5. Optimal order defuzzification of eggs using matlab software

\subsection{Application of the optimal order fuzzy model in the SAFEA application}

Based on the verification of the optimal ordering fuzzy model above, this model will be the basis for developing the optimal order model for the SAFEA application based on the egg agents transaction process and stock conditions. The optimal order model in the SAFEA application will be developed using a database of the variables that affect the egg agent business process. Entity relationship diagram (ERD) optimal order can be seen in the following Figure 6.

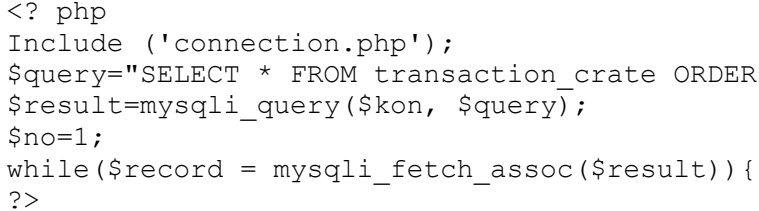




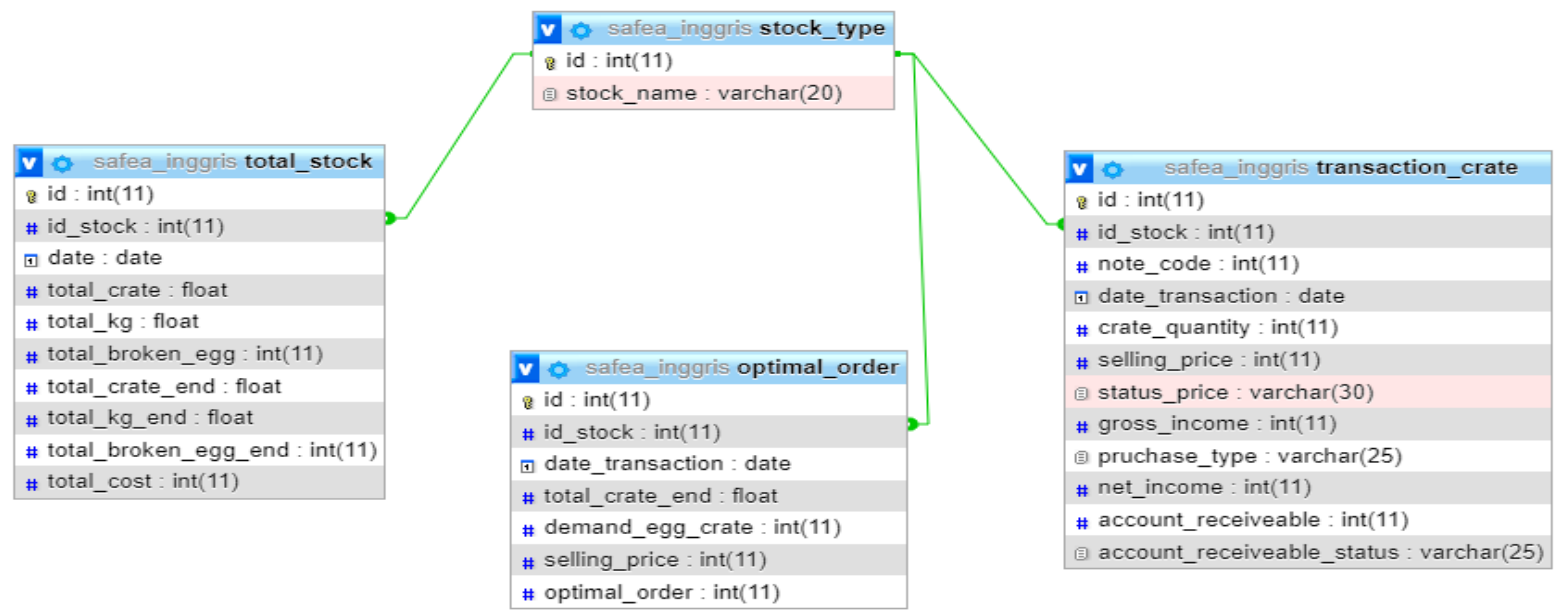

Figure 6. Entity relationship diagram (ERD) optimal order

The three fuzzy input variables will be inputted in real time in the SAFEA application by the user on the crate transaction menu and daily recap. The selling price and the number of requests (Crate quantity) inputted by the operator on the daily crate transaction menu become automatically input into the optimal order menu. SAFEA application egg crate interface can be seen in the following Figure 7.

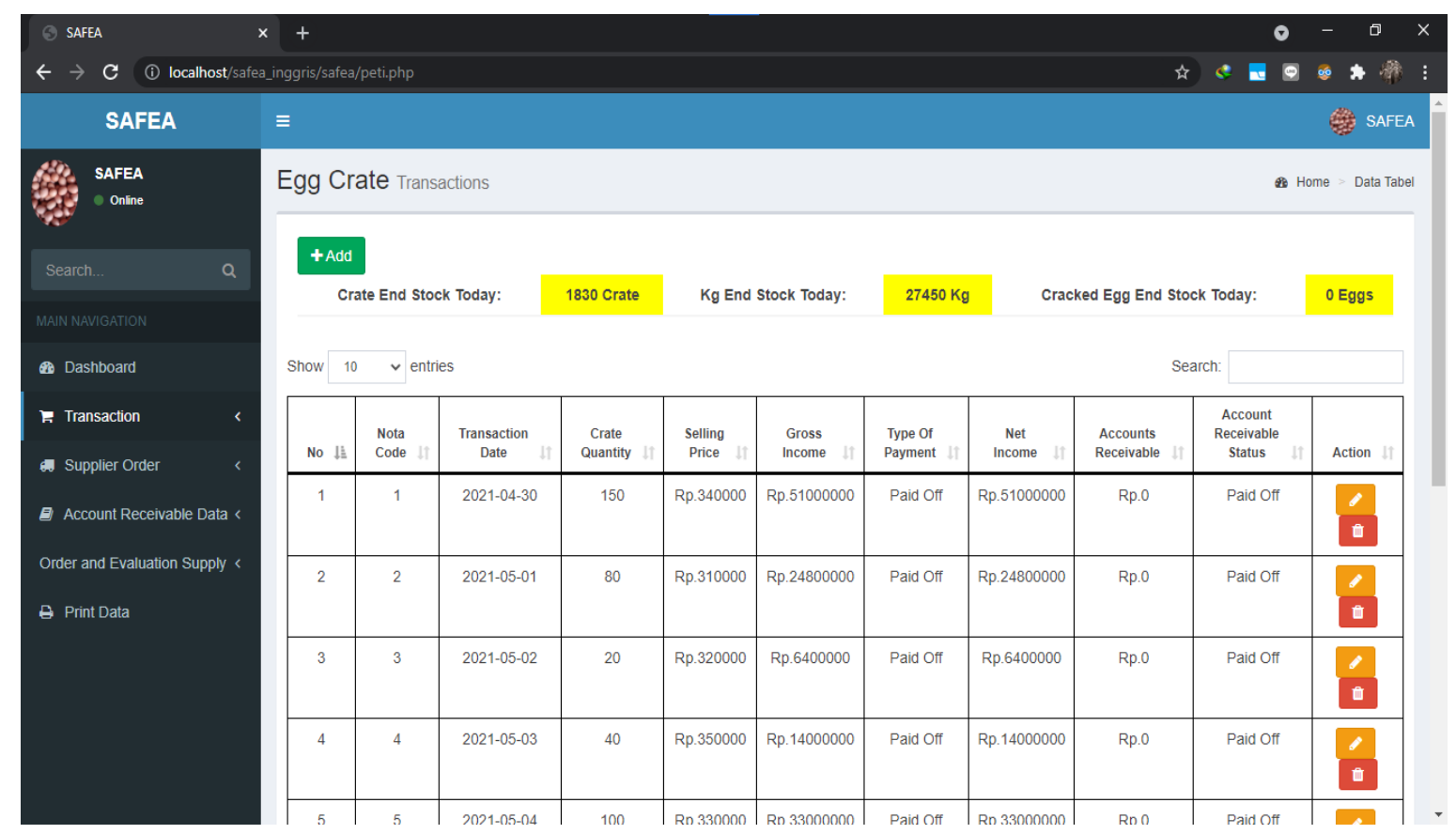

Figure 7. SAFEA application egg crate interface

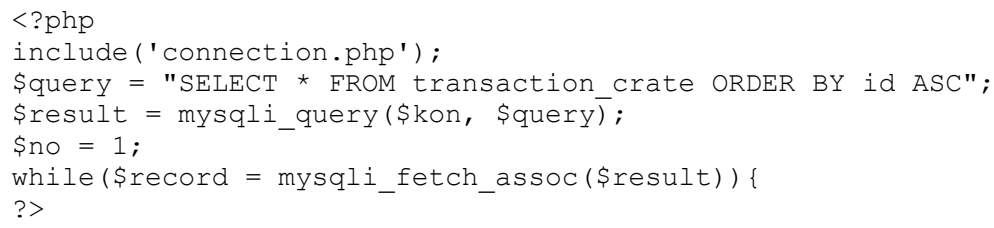

The operator will calculate the quantity of stock based on the number of arrival products and transactions every day. The daily stock recap interface will have a relationship with the optimal order table, 
namely at the end of the egg crate stock field. Egg crate stock will be recapping automatically in the daily recap menu on the SAFEA application. SAFEA application trancation daily recap interfacecan be seen in the following Figure 8.

$<$ ?php

include connection.php';

\$queryl=mysqli_query (\$kon, "SELECT cratetransaction.date, ifnull (sum (income1), '0')

income1, ifnull (sum (income2), '0') income2, ifnull (income3, '0')

income3, ifnull (sum (accounts receivable1), '0')

accounts_receivable1, ifnull (sum (accounts_receivable2), '0')

accounts_receivable2, ifnull (sum (accounts_receivable3), '0')

accounts_receivable3, ifnull (sum(total), ' $\overline{0}$ ') >

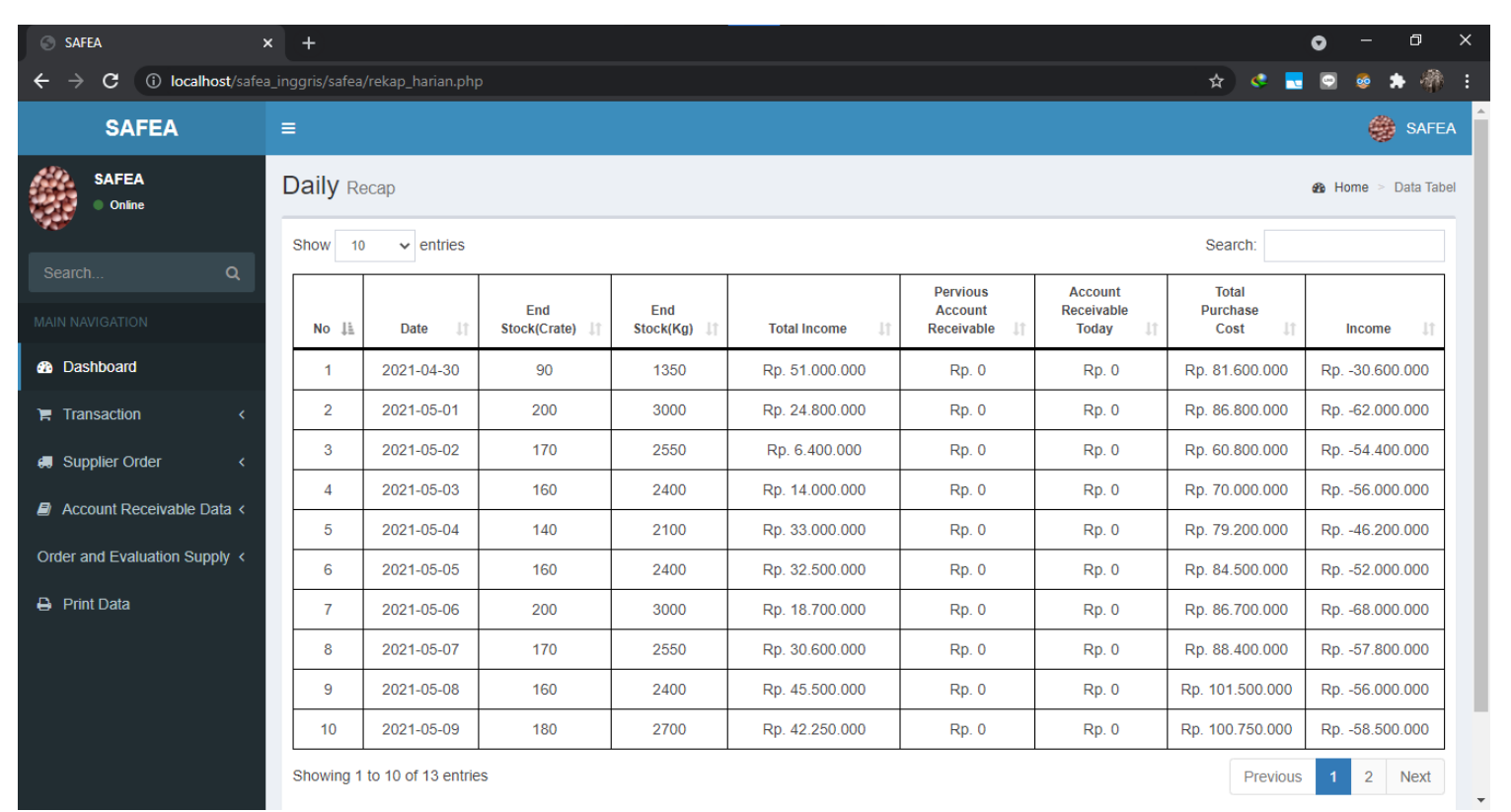

Figure 8. SAFEA application trancation daily recap interface

Based on the transaction recap database and egg stock recap on the SAFEA application, the optimal order defuzzification process will calculate using the Center Of Area (COA) method to get the Egg Agents optimal number of orders. This method will determine the optimal order value based on the egg agent transaction data every day. The SAFEA application will select the moment and area of each input variable to get the optimal number of egg orders to suppliers in real time. SAFEA application optimal order interface can be seen in the following Figure 9.

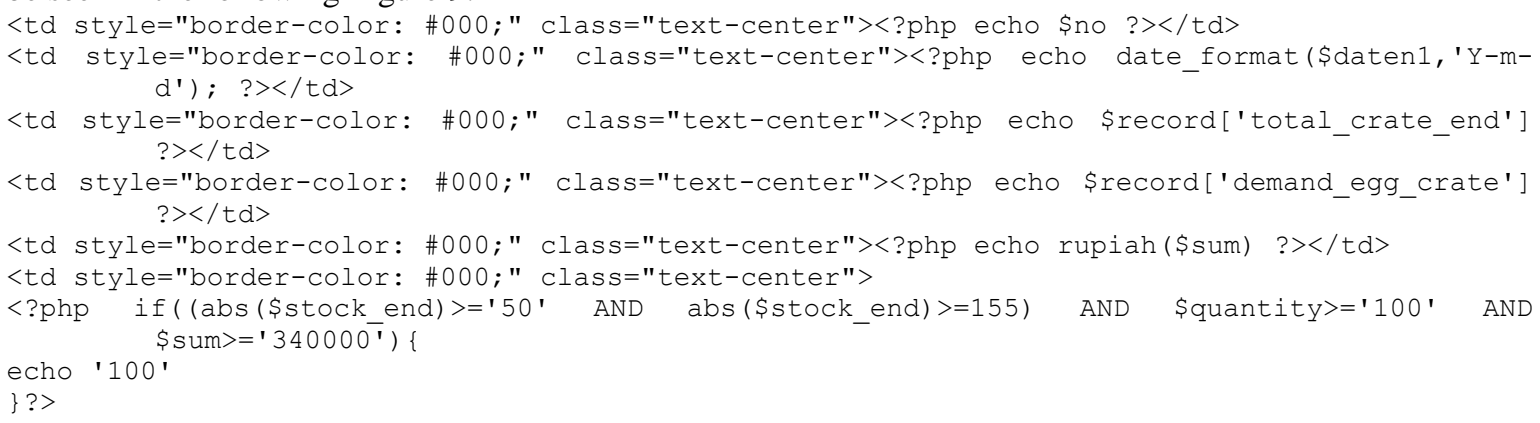

Based on the data processing results on the SAFEA application, the maximum order for 10 transaction days is 110 crates, and the lowest egg order condition to the supplier is 100 crates. The optimal ordering fuzzy model developed in the SAFEA application can help egg agents plan for ordering chicken eggs to optimal suppliers so that the balance of supply and demand for eggs is well maintained so that stock conditions in the warehouse are well maintained. Egg stock evaluation can be seen in the following Figure 10 .

Based on the fuzzy optimal order in Figure 10, the evaluation results with simulation testing related to the final stock comparison between regular orders and fuzzy orders for the last 1 month show that fuzzy

SAFEA application design on determining the optimal order quantity of chicken... (Sesar Husen Santosa) 
orders impact safety stock maintained according to the demand that occurs. On the other hand, regular orders (existing) fluctuate, resulting in a significant buildup of stock in the warehouse every day. In addition, the impact that occurs with the maximum net profit obtained by the egg agent reaches 2 million per day.

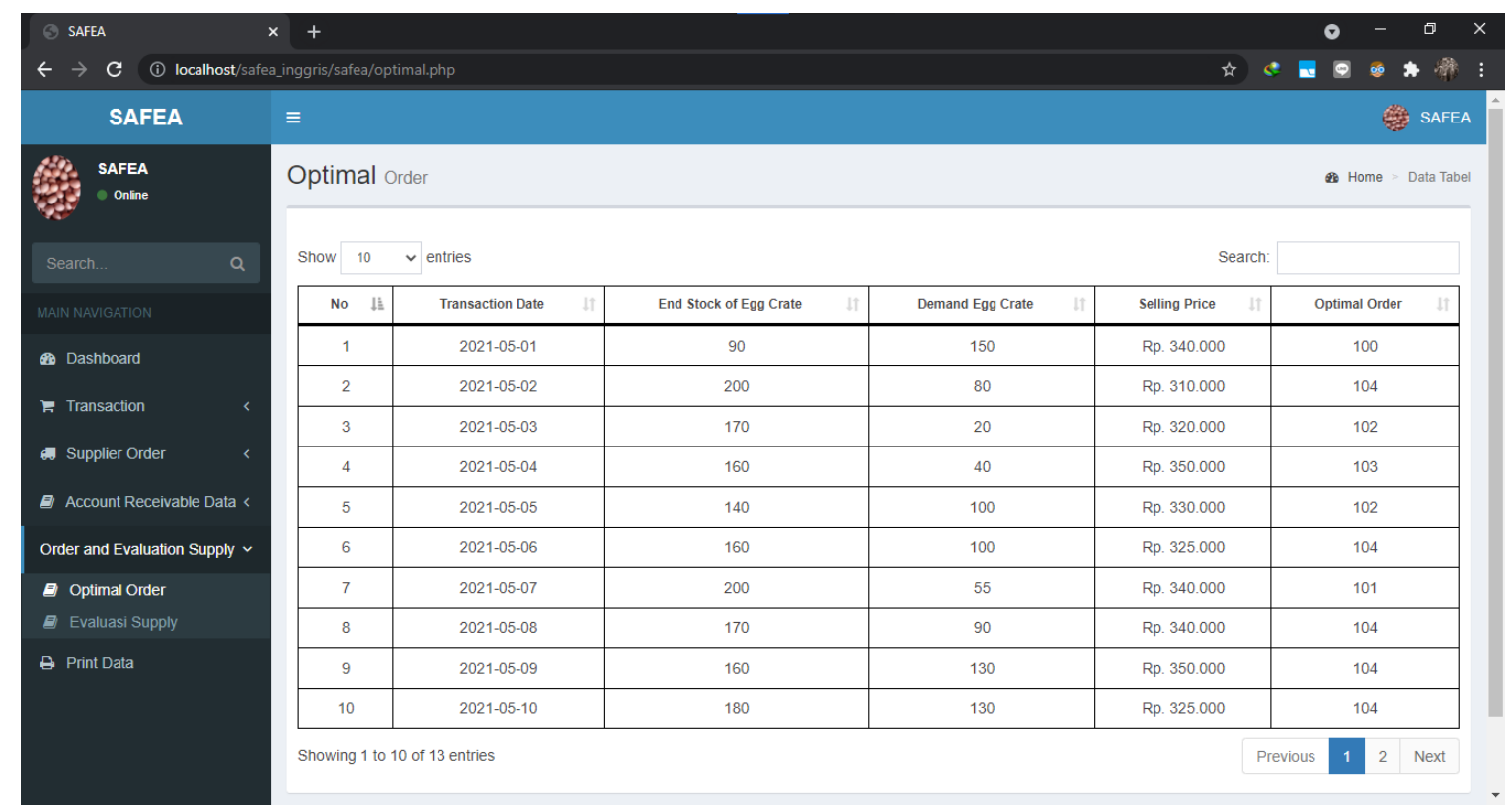

Figure 9. SAFEA application optimal order interface

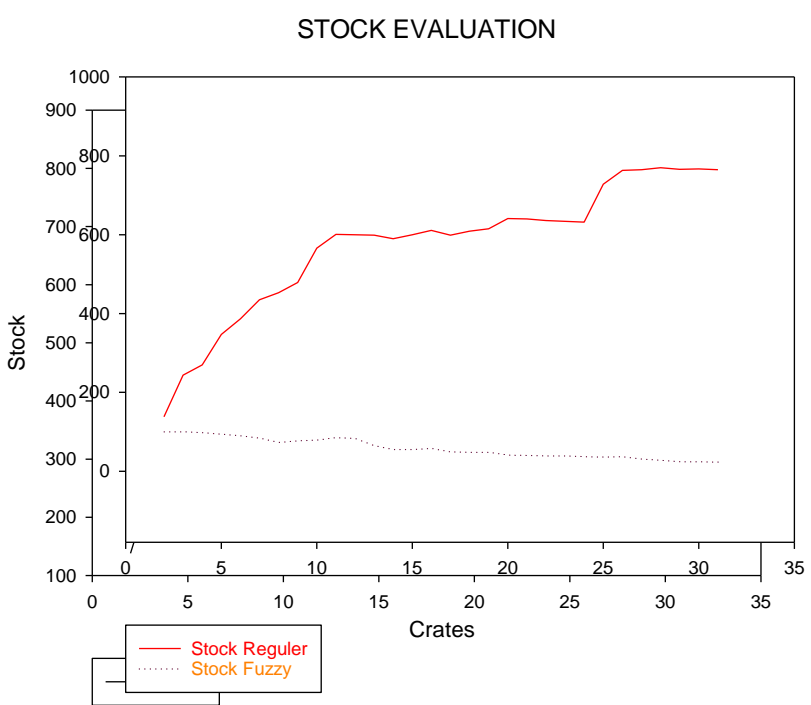

Figure 10. Egg stock evaluation

\section{CONCLUSION}

The development of the optimal ordering model in the SAFEA application uses a fuzzy logic approach with input variables, namely demand (crate), selling price (crate), and final stock (crate) so that it can provide information on the optimal number of orders in real time. Based on the results of transactions using the SAFEA application, the optimum number of orders to suppliers is 100 crates to 104 crates. The stock is always maintained every period of the day, and the eggs do not rot. Future research development can focus on evaluating aspects of the supply process to find alternative egg supply strategies. 


\section{ACKNOWLEDGEMENTS}

The author would like to thank to the Vocational School IPB University for funding this research by Hibah Penelitian Kompetitif Tahun 2020 Sekolah Vokasi IPB Under Contract No.10225/IT3.S3/KS/2020.

\section{REFERENCES}

[1] Y. Shou, J. Shao, K. hung Lai, M. Kang, and Y. Park, "The impact of sustainability and operations orientations on sustainable supply management and the triple bottom line," J. Clean. Prod., vol. 240, p. 118280, 2019. doi: 10.1016/j.jclepro.2019.118280.

[2] D. Li, J. Chen, and Y. Liao, "Optimal decisions on prices, order quantities, and returns policies in a supply chain with two-period selling," " European Journal of Operational Research, Elsevier, vol. 290, no. 3, pp. 1063-1082, doi: 10.1016/j.ejor.2020.08.044.

[3] B. B. Venegas and J. A. Ventura, "A two-stage supply chain coordination mechanism considering price sensitive demand and quantity discounts," Eur. J. Oper. Res., vol. 264, no. 2, pp. 524-533, 2018. doi: 10.1016/j.ejor.2017.06.030

[4] H. Liao and Q. Deng, "EES-EOQ model with uncertain acquisition quantity and market demand in dedicated or combined remanufacturing systems," Appl. Math. Model., vol. 64, pp. 135-167, 2018. doi: 10.1016/j.apm.2018.07.026

[5] B. Rabta, "An Economic Order Quantity inventory model for a product with a circular economy indicator," Comput. Ind. Eng., vol. 140, pp. 1-9, 2019. doi: 10.1016/j.cie.2019.106215

[6] S. Tiwari, L. E. Cárdenas-barrón, A. A. Shaikh, and M. Goh, "Retailer\&\#x02019;s optimal ordering policy for deteriorating items under order-size dependent trade credit and complete backlogging," Comput. Ind. Eng., vol. 139, p. 105559, 2018, doi: 10.1016/j.cie.2018.12.006

[7] R. Wang and J. Wang, "Procurement strategies with quantity-oriented reference point and loss aversion," Omega (United Kingdom), vol. 80, pp. 1-11, 2018. http://dx.doi.org/10.1016/j.omega.2017.08.007.

[8] M. Godichaud and L. Amodeo, "Economic order quantity for multistage disassembly systems," Int. J. Prod. Econ., vol. 199, no. C, pp. 16-25, 2018. doi: 10.1016/j.ijpe.2018.02.008

[9] S. Sinha, N. M. Modak, and S. S. Sana, "assessment considering price sensitive demand," OPSEARCH, vol. 57, pp.88-103, 2019. doi: 10.1007/s12597-019-00406-y

[10] V. A. Wardhany, H. Yuliandoko, A. J. Wildan, T. Iskandar, and M. Udin, "Fuzzy logic decission maker for automatic feeder and water quality monitoring system," International Journal of Informatics and Communication Technology (IJ-ICT), vol. 10, no. 1, pp. 37-45, 2021. doi: 10.11591/ijict.v10i1.pp37-45

[11] J. B. Velandia, C. Enrique, R. Calderón, D. David, and L. Lara, "Optimization techniques on fuzzy inference systems to detect Xanthomonas campestris disease," International Journal of Electrical and Computer Engineering (IJECE), vol. 11, no. 4, pp. 3510-3518, 2021. doi: 10.11591/ijece.v11i4.pp3510-3518

[12] O. Z. Mustapha, M. Ali, Y. F. Hu, and R. A. Abd-alhameed, "Service-aware LSP selection with fuzzy based packet scheduling scheme for non - real time traffics," International Journal of Informatics and Communication Technology (IJ-ICT), vol. 10, no. 2, pp. 126-139, 2021. doi: 10.11591/ijict.v10i2.pp126-139

[13] A. Keykavoussi and A. Ebrahimi, "Total Quality Management \& Business Excellence Using fuzzy cost - time profile for effective implementation of lean programmes; SAIPA automotive manufacturer , case study," Total Qual. Manag., vol. 31, no. 13-14, pp. 1519-1543, 2018. doi: 10.1080/14783363.2018.1490639

[14] Z. Massaq, A. Abounada, and M. Ramzi, "Fuzzy and predictive control of a photovoltaic pumping system based on three-level boost converter," Bulletin of Electrical Engineering and Informatics (BEEI), vol. 10, no. 3, pp. 11831192, 2021. doi: 10.11591/eei.v10i3.2605

[15] M. Y. Hassan and S. S. Ezzaten, "Interval type-2 fuzzy logic controller design for distillation column process," IAES International Journal of Robotics and Automation (IJRA), vol. 8, no. 3, pp. 155-163, 2019. doi: 10.11591/ijra.v8i3.pp155-163

[16] P. Salam and D. Ibrahim, "An educational fuzzy temperature control system," International Journal of Electrical and Computer Engineering (IJECE), vol. 10, no. 3, pp. 2463-2473, 2020. doi: 10.11591/ijece.v10i3.pp2463-2473

[17] N. Ikken, N. Tariba, A. Bouknadel, A. Haddou, H. El Omari, and H. El Omari, "A fuzzy rule based approach for islanding detection in grid connected inverter systems," International Journal of Electrical and Computer Engineering (IJECE), vol. 11, no. 6, pp. 4759-4766, 2021. doi: 10.11591/ijece.v11i6.pp4759-4766

[18] M. Alenezi, "Ontology-based context-sensitive software security knowledge management modeling," International Journal of Electrical and Computer Engineering (IJECE), vol. 10, no. 6, pp. 6507-6520, 2020. doi: 10.11591/ijece.v10i6.pp6507-6520

[19] K. Makhloufi, I. K. Bousserhane, and S. A. Zegnoun, "Adaptive fuzzy sliding mode controller design for PMLSM position control," International Journal of Power Electronics and Drive Systems (IJPEDS), vol. 12, no. 2, pp. 674684, 2021. doi: 10.11591/ijpeds.v12.i2.pp674-684

[20] N. Tidjani and A. Guessoum, "Augmented robust T-S fuzzy control based PMSG wind turbine improved with H $\infty$ performance," International Journal of Power Electronics and Drive Systems (IJPEDS), vol. 12, no. 1, pp. 585596, 2021. doi: 10.11591/ijpeds.v12.i1.pp585-596

[21] M. Moutchou, A. Jbari, and Y. Abouelmahjoub, "Implementation of reduced induction machine fuzzy logic control , based on dSPACE-1104 R \& D controller board," International Journal of Power Electronics and Drive Systems (IJPEDS), vol. 12, no. 2, pp. 1015-1023, 2021. doi: 10.11591/ijpeds.v12.i2.pp1015-1023

[22] A. Mousmi, A. Abbou, and Y. El Houm, "Real-time implementation of a novel hybrid fuzzy sliding mode control of a BLDC motor," International Journal of Power Electronics and Drive Systems (IJPEDS), vol. 10, no. 3, pp.

SAFEA application design on determining the optimal order quantity of chicken... (Sesar Husen Santosa) 
1167-1177, 2019. doi: 10.11591/ijpeds.v10.i3.pp1167-1177

[23] G. A. M. Madrigal et al., "Fuzzy logic-based maximum power point tracking solar battery charge controller with backup stand-by AC generator," Indonesian Journal of Electrical Engineering and Computer Science, vol. 16, no. 1, pp. 136-146, 2019. doi: 10.11591/ijeecs.v16.i1.pp136-146

[24] Z. Kamis, M. Ruddin, A. Ghani, M. N. Kamarudin, H. Nizam, and M. Shah, "Fuzzy controlled SVC for power system damping," Indonesian Journal of Electrical Engineering and Computer Science, vol. 18, no. 3, pp. 16731678, 2020. doi: 10.11591/ijeecs.v18.i3.pp1673-1678

[25] S. M. Praveena, R. Kanmani, and A. K. Kavitha, "A neuro fuzzy image fusion using block based feature level method," Int. J. Informatics Commun. Technol., vol. 9, no. 3, p. 195, 2020. doi: 10.11591/ijict.v9i3.pp195-204

[26] R. Thilahar C. and S. R., "Fuzzy neuro-genetic approach for feature selection and image classification in augmented reality systems," IAES Int. J. Robot. Autom., vol. 8, no. 3, p. 194, 2019. doi: 10.11591/ijra.v8i3.pp194204

[27] M. Haddin, A. Marwanto, A. Suprajitno, and M. Ismail, "Fuzzy logic applications for data acquisition systems of practical measurement," International Journal of Electrical and Computer Engineering (IJECE), vol. 10, no. 4, pp. 3441-3450, 2020. doi: 10.11591/ijece.v10i4.pp3441-3450

[28] N. Vafaei, R. A. Ribeiro, and L. M. Camarinha-Matos, "Fuzzy early warning systems for condition based maintenance," Comput. Ind. Eng., vol. 128, pp. 736-746, 2019. https://doi.org/10.1016/j.cie.2018.12.056

[29] J. Noh and J. S. Kim, "Cooperative green supply chain management with greenhouse gas emissions and fuzzy demand,” J. Clean. Prod., vol. 208, pp. 1421-1435, 2019. doi: 10.1016/j.jclepro.2018.10.124

[30] S. K. Mangla, S. Luthra, and S. Jakhar, "Benchmarking the risk assessment in green supply chain using fuzzy approach to FMEA: Insights from an Indian case study," Benchmarking, vol. 25, no. 8, pp. 2660-2687, 2018. doi: 10.1108/BIJ-04-2017-0074

[31] G. Hu, E. Bakhtavar, K. Hewage, M. Mohseni, and R. Sadiq, "Heavy metals risk assessment in drinking water : An integrated probabilistic- fuzzy approach," J. Environ. Manage., vol. 250, no. June, p. 109514, 2019. doi: 10.1016/j.jenvman.2019.109514

[32] J. Qin, X. Liu, and W. Pedrycz, "An extended TODIM multi-criteria group decision making method for green supplier selection in interval type-2 fuzzy environment," Eur. J. Oper. Res., vol. 258, no. 2, pp. 626-638, 2017. http://dx.doi.org/10.1016/j.ejor.2016.09.059

[33] A. Iqbal and B. Soo, "Computers \& Industrial Engineering A multi-constrained supply chain model with optimal production rate in relation to quality of products under stochastic fuzzy demand," Comput. Ind. Eng., vol. 149, no. July, p. 106814, 2020. doi: 10.1016/j.cie.2020.106814

[34] M. Zheng, K. Wu, C. Sun, and E. Pan, "Advanced Engineering Informatics Optimal decisions for a two-echelon supply chain with capacity and demand information," Adv. Eng. Informatics, vol. 39, no. July 2018, pp. 248-258, 2019. doi: 10.1016/j.aei.2019.01.008

[35] Z. T. Wilson and N. V. Sahinidis, "The ALAMO approach to machine learning," Comput. Chem. Eng., vol. 106, pp. 785-795, 2017. doi: http://dx.doi.org/10.1016/j.compchemeng.2017.02.010

[36] S. Mullainathan and J. Spiess, "Machine learning: An applied econometric approach," J. Econ. Perspect., vol. 31, no. 2 , pp. $87-106,2017$. doi: $10.1257 /$ jep. 31.2 .87

[37] W. Hassan, T. Chou, O. Tamer, J. Pickard, P. Appiah-kubi, and L. Pagliari, "Cloud computing survey on services , enhancements and challenges in the era of machine learning and data science," International Journal of Informatics and Communication Technology (IJ-ICT), vol. 9, no. 2, pp. 117-139, 2020. doi: 10.11591/ijict.v9i2.pp117-139

[38] A. B., K. Krishi, M. M., M. Daaniyaal, and A. H. S., "Hand gesture recognition using machine learning algorithms," Comput. Sci. Inf. Technol., vol. 1, no. 3, pp. 116-120, 2020. doi: 10.11591/csit.v1i3.p116-120

[39] B. Mahesh, "Machine Learning Algorithms - A Review," International Journal of Science and Research (IJSR), vol. 9. no. 1, pp. 381 - 386, October, 2020. doi: 10.21275/ART20203995.

[40] T. Alam, "Performance evaluation of blockchains in the internet of things," International Journal of Power Electronics and Drive Systems (IJPEDS), vol. 1, no. 3, pp. 93-97, 2020. doi: 10.11591/csit.v1i3.p93-97 doi: 10.11591/ijpeds.v12.i1.pp558-566

[41] S. R. Mestha and P. P. A. J, "Investigation of reliability assessement in power electronics circuits using machine learning," International Journal of Power Electronics and Drive Systems (IJPEDS), vol. 12, no. 1, pp. 558-566, 2021. doi: 10.11591/ijpeds.v12.i1.pp558-566

[42] L. Imen and L. Djamel, "Power flow variation based on extreme learning machine algorithm in power system," International Journal of Power Electronics and Drive Systems (IJPEDS), vol. 10, no. 3, pp. 1244-1254, 2019. doi: 10.11591/ijpeds.v10.i3.pp1244-1254

[43] K. G. Liakos, P. Busato, D. Moshou, and S. Pearson, "Machine Learning in Agriculture: A Review," Sensors (Basel), vol. 18, no. 8, p. 2674, 2018, doi: 10.3390/s18082674

[44] T. A. Assegie and P. S. Nair, "Handwritten digits recognition with decision tree classification: A machine learning approach," Int. J. Electr. Comput. Eng., vol. 9, no. 5, pp. 4446-4451, 2019. doi: 10.11591/ijece.v9i5.pp4446-4451

[45] S. R. Salkuti, "A survey of big data and machine learning," Int. J. Electr. Comput. Eng., vol. 10, no. 1, pp. 575580, 2020. doi: 10.11591/ijece.v10i1.pp575-580

[46] Željko Stević, "Sustainable supplier selection in healthcare industries using a new MCDM method: Measurement Alternatives and Ranking according to COmpromise Solution," Computers \& Industrial Engineering, vol. 140, p. 106231, 2020, doi: https://doi.org/10.1016/j.cie.2019.106231.

[47] I. S. K. Ã, "Estimating the optimal order quantity and the maximum expected profit for single-period inventory decisions," Omega, vol. 38, no. 3-4, pp. 218-227, 2010. doi: 10.1016/j.omega.2009.09.005 
[48] E. Pourjavad and A. Shahin, "The Application of Mamdani Fuzzy Inference System in Evaluating Green Supply Chain Management Performance," Int. J. Fuzzy Syst., vol. 20, no. 3, pp. 901-912, 2018. doi: 10.1007/s40815-0170378-y

[49] R. Rajesh, "A fuzzy approach to analyzing the level of resilience in manufacturing supply chains," Sustain. Prod. Consum., vol. 18, pp. 224-236, 2019. doi: 10.1016/j.spc.2019.02.005

[50] J. Rezaei and R. Ortt, "Supplier segmentation using fuzzy logic," Ind. Mark. Manag., vol. 42, no. 4, pp. 507-517, 2013. http://dx.doi.org/10.1016/j.indmarman.2013.03.003

[51] P. Angelov, "An approach for fuzzy rule-base adaptation using on-line clustering," Int. J. Approx. Reason., vol. 35, no. 3, pp. 275-289, 2004. doi: 10.1016/j.ijar.2003.08.006

[52] Q. Zhou, W. Wu, D. Liu, K. Li, and Q. Qiao, "Estimation of corrosion failure likelihood of oil and gas pipeline based on fuzzy logic approach,” EFA, vol. 70, pp. 48-55, 2016. doi: 10.1016/j.engfailanal.2016.07.014

[53] L. Alsaber, E. Al Elsheikh, S. Aljumah, and N. S. Mohd Jamail, "Perspectives on the adherance to scrum rules in software project management," Indones. J. Electr. Eng. Comput. Sci., vol. 21, no. 1, pp. 360-366, 2021. doi: 10.11591/ijeecs.v21.i1.pp360-366

[54] A. Baharum et al., "Mobile learning application: Flipped classroom," Indones. J. Electr. Eng. Comput. Sci., vol. 17, no. 2, pp. 1084-1090, 2020. doi: 10.11591/ijeecs.v17.i2.pp1084-1090

[55] Kamesh and N. Sakthi Priya, "A survey of cyber crimes Yanping," Secur. Commun. Networks, vol. 5, no. June, pp. 422-437, 2012. doi: 10.1002/sec

[56] R. de Hoog, T. de Jong, F. de Vries, "Constraint-Driven Software Driven: An Escape From the Waterfall Model," Performance ImprovementQuarterly, vol. 7, no. 3, pp. 48-63, 1994, doi: https://doi.org/10.1111/j.19378327.1994.tb00637.x.

[57] W. W. Widiyanto and S. Wulandari, "Accuracy Implementation of Medical Record Management Information System with Waterfall Design System and ISO 9126," Asian J. Res. Comput. Sci., vol. 6, no. 2, pp. 36-45, 2020. doi: 10.9734/ajrcos/2020/v6i230156

[58] W. Elmenreich, "A review on system architectures for sensor fusion applications," Lect. Notes Comput. Sci. (including Subser. Lect. Notes Artif. Intell. Lect. Notes Bioinformatics), vol. 4761 LNCS, pp. 547-559, 2007. doi: 10.1007/978-3-540-75664-4_57

[59] S. M. Mitchell and C. B. Seaman, "A comparison of software cost, duration, and quality for waterfall vs. iterative and incremental development: A systematic review," 2009 3rd Int. Symp. Empir. Softw. Eng. Meas. ESEM 2009, no. February 2008, pp. 511-515, 2009. doi: 10.1109/ESEM.2009.5314228

[60] L. R. Vijayasarathy and C. W. Butler, "Choice of Software Development Methodologies: Do Organizational, Project, and Team Characteristics Matter?," in IEEE Software, vol. 33, no. 5, pp. 86-94, Sept.-Oct. 2016, doi: 10.1109/MS.2015.26.

\section{BIOGRAPHIES OF AUTHORS}

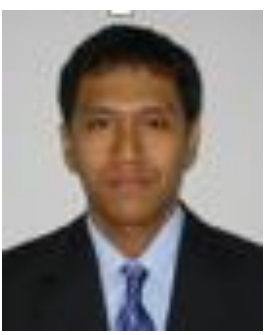

Sesar Husen Santosa, S.TP, MM was born in Bogor, West Java Indonesia in 1984. He received the S.TP degrees in Agroindustrial Technology IPB University, Indonesia in 2007 and M.M degree in Magister Manajemen from IPB University in 2009. Since 2013 he has been a lecture with the Study Program of Industrial Management, College of Vocational Studies, IPB University. His research interests include Fuzzy Logic Approach, Production Planning and Total Productive Maintenance.

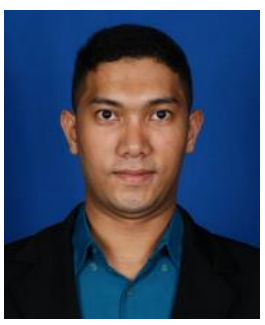

Agung Prayudha Hidayat was born in Bogor, West Java Indonesia in 1992. He received the S.T degrees in Postal Polytechnic Indonesia in 2014 and M.T degree in Magister Transportation from Bandung of Institute Technology in 2018.Since 2014 he has been a lecture with the Study Program of Industrial Management, College of Vocational Studies, IPB University. His research interests in Logistics and Transportation.

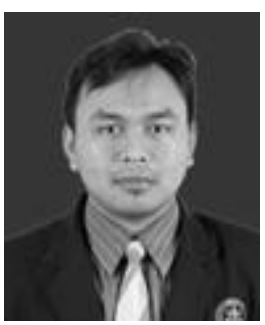

Ridwan Siskandar, S.Si, M.Si was born in Kuningan, West Java, Indonesia in 1989. He received the S.Si degrees in physic from IPB University, Indonesia, in 2011 and the M.Si degree in biophysical from IPB University, Indonesia, in 2014. Since 2014 he has been a Lecturer with the Study Program of Computer Engineering, College of Vocational Studies, IPB University, Indonesia. His research interests include material physics, sensors, embedded systems, automation and the internet of thing. 